\title{
Um Ambiente Dinâmico Para o Ensino das Secções Cônicas
}

\author{
A Dynamic Environment for Teaching the Conic Sections
}

\begin{abstract}
João Paulo Lima*1
Mestre em matemática pela Universidade Federal Rural do Semiárido (UFERSA-RN) e Professor de matemática do Instituto Federal de Educão, Ciência e Tecnologia do Ceará - campus Limoeiro do Norte. Brasil
\end{abstract}

\begin{abstract}
Resumo
Neste trabalho será feita a apresentação de um ambiente dinâmico concebido para o ensino das secções cônicas. O ambiente é uma página da web onde o aluno, orientado pelo professor, constrói seu conhecimento por meio da exploração de objetos digitais construídos com auxílio do software de geometria dinâmica GeoGebra. Serão descritas as possibilidades de utilização de alguns dos diversos elementos dinâmicos do ambiente. Por fim, algumas recomendações para os professores que desejam incrementar suas aulas de geometria com esta nova ferramenta de ensino.
\end{abstract}

Palavras-chave: Ensino. Cônicas. Tecnologias no Ensino de Matemática. Geometria Dinâmica. GeoGebra

\begin{abstract}
In this paper presenting a dynamic environment designed for teaching of conic sections will be taken. The environment is a web page where the student, guided by the teacher, building their knowledge through exploration of digital objects constructed with the aid of dynamic geometry GeoGebra software. The possibilities of using some of the many dynamic elements of the environment will be described. Finally, some recommendations for teachers who wish to enhance their geometry classes with this new teaching tool.
\end{abstract}

Keywords: Teaching, Conics. Technologies in Mathematics Teaching, Dynamic Geometry. GeoGebra 


\section{Introdução}

O que você sabe sobre as Seções Cônicas: Elipse, Parábola e Hipérbole?

Caso fizéssemos essa pergunta aos alunos egressos do Ensino Médio, possivelmente não obteríamos respostas, ou caso houvesse, provavelmente seriam incompletas, difusas e superficiais, com menção exclusivamente ao fato de tratar-se de curvas e terem, cada uma delas, uma equação associada. Essa conclusão fundamenta-se na forma como esse assunto é ensinado no Ensino Básico atual.

Através da análise dos diversos livros didáticos de Matemática, observa-se que a grande maioria desses textos trata o assunto "Cônicas" apenas sob o ponto de vista de equações algébricas. Quanto à origem histórica do tema, às propriedades geométricas, às relações entre as curvas, às aplicações, etc., quando mencionados, são pequenas passagens ou leituras complementares, com informações superficiais.

É muito provável que essa abordagem limitada e superficial das cônicas nos livro didáticos seja um dos grandes motivos da não valorização do tema pelos alunos, sentimento compartilhado, pela maioria dos próprios professores, que por usar, na maioria das vezes, o livro didático como única fonte de pesquisa, deixa de reconhecer a beleza, história, importância e utilidade do tema. Valores esses perceptíveis quando se explora o conhecimento acumulado ao longo da história das seções cônicas.

Outro fator que contribui para a má compreensão do tema e baixa aceitação por porte dos alunos é a forma tradicional com que o assunto é ministrado, isto é, o ensino restrito ao uso da lousa, giz e livro didático. Tal metodologia de ensino, aliado à explanação não contextualizada, limitada e superficial do assunto, certamente contribui para torná-lo pouco atrativo para os alunos e, inclusive, para os professores.

Segundo D'ambrósio (2003) a verdadeira aprendizagem em matemática, em especial em Geometria, deve passar necessariamente pelas etapas de exploração concreta, experimentação, resolução de problemas, elaboração de conjecturas, justificativas informais e provas. Nessa concepção, ver-se a necessidade de substituir os processos de ensino que priorizam a exposição, que levam a um receber passivo do conteúdo e que não estimulam a participação dos alunos, para que os mesmo deixem de ver a matemática como algo acabado e cuja transmissão de conteúdos lhes parece um conjunto estático de conhecimentos e técnicas.

Visando contribuir com essa nova forma de pensar sobre o ensino de matemática, sobretudo o de Geometria, neste trabalho será apresentado uma nova ferramenta para ensino das Seções Cônicas. Tal dispositivo consiste num Ambiente Dinâmico de Ensino das Seções Cônicas (ADESC).

A ferramenta é inovadora, visto que procura valorizar os fatos históricos, os autores do processo, dando ênfase às relações que existem entre as curvas, valorizando a exploração das mesmas sob o ponto de vista geométrico com intuito de motivar e preparar o aluno para exploração algébrica do tema. No ADESC, o estudo das cônicas contempla desde os fatos históricos, iniciando com o Problema de Delos (O clássico problema da Duplicação do Cubo), passando pela análise analítica das curvas e finalizando com suas modernas aplicações nas ciências atuais. Todo o estudo é auxiliado por elementos visuais que facilitam a compreensão e exploração das informações teóricas.

\section{Conhecendo o ADESC.}

O "Ambiente Dinâmico de Ensino das Seções Cônicas ADESC" (ver ADE (2014) é uma ferramenta de ensino e aprendizagem que visa contribuir para uma maior eficiência no ensino das cônicas. Construído na forma de página da world wide web (www), o ambiente pode ser utilizado de modo online, acessando o endereço (www.adesc.blog.br) ou off-line, podendo o download ser feito em (http://1drv.ms/PAVdnV). O ambiente possui diversos elementos dinâmicos baseados em construções feitas no software livre de geometria dinâmica, GeoGebra, criado em 2001 pelo Professor austríaco Markus Hohenwarter, disponível em www.geogebra.org.

A proposta do ADESC é apresentar uma nova forma de ensino das Seções Cônicas, tanto com relação aos conteúdos abordados quanto a metodologia de apresentação do mesmo. No que concerne ao conteúdo, o ADESC foi desenvolvido seguindo integralmente a sequência de conteúdos para o ensino das Seções Cônicas proposta em LIMA (2014). Já com relação à metodologia de apresentação do conteúdo, o ambiente traz o diferencial do dinamismo e a praticidade inerente a um ambiente de ensino dinâmico. Recheado de construções geométricas de livre manipulação, o ambiente propicia ao usuário a possibilidade de interagir com a matemática, manipulando entes geométricos, observando, construindo, resolvendo problemas e consequentemente, inferindo sobre propriedades, relações, condições, bem como descobrindo novos conceitos envolvidos.

$\mathrm{O}$ ambiente foi concebido a partir de uma abordagem dinâmica do assunto, buscando contribuir para a compreensão e articulação dos conteúdos envolvidos, de forma autônoma e criativa, integrando as formas de pensamento algébrico e geométrico. A abordagem concreta-computacional apresentada no ADESC, antes de direcionar o estudo diretamente para a álgebra das cônicas, possibilita o aluno construir e/ou manipular ob- 
jetos digitais representativos das situações matemáticas em estudo. A manipulação destes objetos no ambiente computacional ajuda no estabelecimento de conjecturas e justificativas e esta é uma parte considerável do trabalho de ensinar geometria, para o qual a Geometria Dinâmica (G.D.) contribui efetivamente. Desta forma, as representações neste ambiente ajudam a concretizar o simbólico, fornecendo aos alunos a base experimental necessária às abstrações inerentes à prova matemática.

Numa visão geral, o ADESC estrutura-se numa sequencia de páginas da web, todas elas com links e botões que permitem uma navegação sobre todo o ambiente de maneira fácil e integrada. São elas:

- Home;

- Página 0: Índice;

- Página 1: Origem das seções cônicas;

- Página 2: As contribuições de Apolônio;

- Página 3: Cônicas como lugar geométrico no plano;

- Página 4: Estudo analítico das cônicas;

- Página 5: Aplicação das cônicas;

- Página 6: Apêndice.

Em cada uma das páginas 1 a 5, o conteúdo referente ao título de cada uma delas aparece na forma de texto, acompanhado de ilustrações, vídeos e construções dinâmicas. São essas "Construções" que fazem o diferencial da apresentação do conteúdo por meio do ambiente ADESC. Nessas páginas o usuário pode construir ou manipular entes geométricos e comprovar mediante observações, as propriedades, as leis, as definições e as relações que tenham sido mencionadas no texto teórico.

As "Construções" aparecem no ambiente numa moldura dinâmica (ver Figura 1) que se insere no meio do texto, quando necessário uma observação e/ou manipulação de elementos geométricos para facilitar a compreensão das informações expostas naquele momento.

A moldura inicia com uma "Barra de Título", com informações de identificação, como numeração e assunto abordado. No Quadro de Orientações (QO) (quadro verde logo abaixo da barra de título) aparecem os procedimentos que deverão ser realizados para um manuseio adequado da construção, bem como, dicas, descrições, definições, passo-a-passos para a realização de construções geométricas quando necessário. Os textos nesse quadro aparecerão na cor "Branca", quando tratar-se de procedimento que deva ser realizado pelo usuário para construção e/ou manipulação de determinado objeto, ou na cor "Amarela", quando tratar-se de orientações, comandos, dicas ou informações sobre os procedimentos a serem executados. Assim, por exemplo, ainda na Figura 1, no passo "10" do Quadro de Orientação, o usuário deve construir a mediatriz $M$ do segmento $\overline{A C}$ e uma forma de faze-lo é digitando o comando $M=$ mediatriz $[A, C]$ na barra de comandos do GeoGebra que aparecerá na região em branco logo abaixo do quadro de orientações.

O Quadro de Trabalho (QT) (quadro branco no centro da moldura) é o local onde serão construídos e/ou visualizados os objetos digitais. Nesse quadro, aparecerá a tela de trabalho do GeoGebra com objetos digitais já construídos (no caso em que é necessário apenas a manipulação) ou em condições de serem realizadas construções, conforme informações presentes no Quadro de Orientações.

Ao final da moldura, encontram-se os botões de manipulação. Segue a função de cada um deles:

Faça: Abre o software GeoGebra no quadro de trabalho, pronto para realização de construções.

Veja: Executa um objeto digital no quadro de trabalho, permitindo a sua manipulação.

Atividade: Abre uma atividade que explora os conceitos, definições e propriedades relacionadas à construção.

Dica: Abre uma tela no estilo Pop up com dicas rápidas e atalhos de mouse e teclado para melhor manuseio do GeoGebra.

Ajuda: Abre em uma nova janela, no formato de arquivo Portable Document Format (pdf), um manual simplificado do GeoGebra, especialmente construído para usuários do ADESC.

Limpar: Limpa o quadro de trabalho.

Índice: Abre a página "Apêndice - A1 - Índice das construções" do ADESC. Onde é possível ver resumidamente todas as construções presentes no ambiente e navegar por cada uma delas.

Os botões em cinza-claro estão inativos para esta determinada moldura, podendo em outros casos aparecer ativos e com funções específicas.

A seguir, serão apresentadas algumas construções do ADESC. Ao todo, o ambiente disponibiliza 28 delas. Tem-se consciência que a melhor descrição ainda não será suficiente para transmitir a satisfação e o prazer de se construir o conhecimento mediante a manipulação de objetos digitais em um ambiente dinâmico. Portanto, fazse necessário que o leitor, após a leitura das descrições abaixo, acesse o ambiente e tire suas próprias conclusões. 


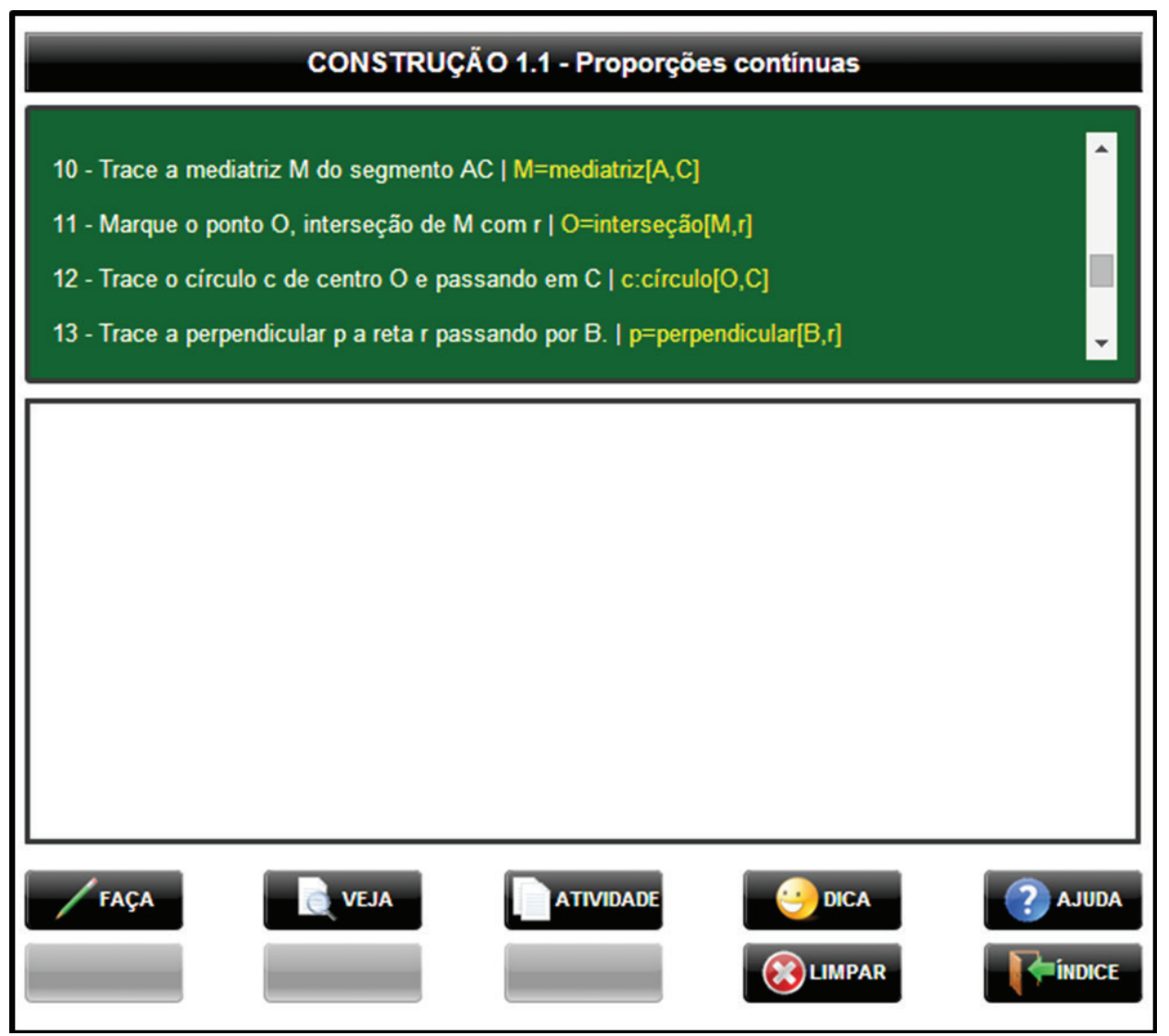

Figura 1: Moldura para construção/manipulação dos elementos dinâmicas do ADESC.

3 Construção: cônicas segundo Apolônio.

Conforme Boyer (1996) o matemático Apolônio nasceu em Perga (sul da Ásia Menor) e acredita-se tenha vivido por volta de 262 a 190 a.C. Ele, juntamente com Euclides e Arquimedes, produziu obras que justificaram o nome "Idade Áurea da Matemática Grega" dado à época em que viveram.

Dos muitos tratados de Apolônio, a sua obra "As Cônicas", foi certamente a sua obra prima. Sendo composta por oito volumes, apenas os sete primeiros foram preservados até os dias atuais, sendo os quatro primeiros em grego e os demais, traduções em árabe por Thabit Ibn Querra (836 a 901). Em 1710, Edmund Halley (16561742) traduziu os sete volumes sobreviventes para o latim, possibilitando as demais traduções para as outras línguas modernas.

Quando Apolônio escreveu seu tratado sobre as cônicas, outras exposições já tinham sido escritas sobre essas curvas. Mas "As Cônicas" foi de suma importância para o desenvolvimento desse assunto no campo da Matemática. Antes do tempo de Apolônio, segundo Boyer (1996), as cônicas eram obtidas seccionando três tipos diferentes de cones por planos sempre perpendiculares a uma geratriz do mesmo. Assim, conforme o ângulo do vértice do cone fosse, agudo, reto ou obtuso, a curva resultante da secção era uma elipse, uma parábola ou uma hipérbole, respectivamente. Esse método era usado pelo matemático grego Menaecmus (380 - 320 a.C.).

Na Figura 2, vê-se uma construção do ADESC que mostra como as cônicas eram obtidas pelo método acima descrito de Menaecmus. Nela, o usuário pode alterar a altura $(h)$ e o raio $(r)$ da base do cone para obter cones de ângulo do vértice agudo, reto ou obtuso. É possível modificar a posição em que o plano secciona a geratriz do cone e verificar em cada caso, as seções cônicas obtidas. Para isso, basta alterar o valor do seletor alfa $(\alpha)$. Pode-se ainda rotacionar o objeto e visualizálo sobre todas as orientações, o que possibilita uma exploração mais completa e facilita a materialização das informações teóricas do texto.

Dessa forma, compreender e aceitar as informações sobre as definições de cada uma das cônicas segundo Menaecmus se torna uma tarefa menos abstrata e o conhecimento adquirido passa a ser mais sólido e rico em detalhes. Por exemplo, alterando apenas a posição de secção do plano em relação à geratriz do cone, é possível perceber que o tipo de cônica não se altera, nesse caso há apenas variação no comprimento de seus elementos, como por exemplo, o tamanho do latus rectum, segui- 


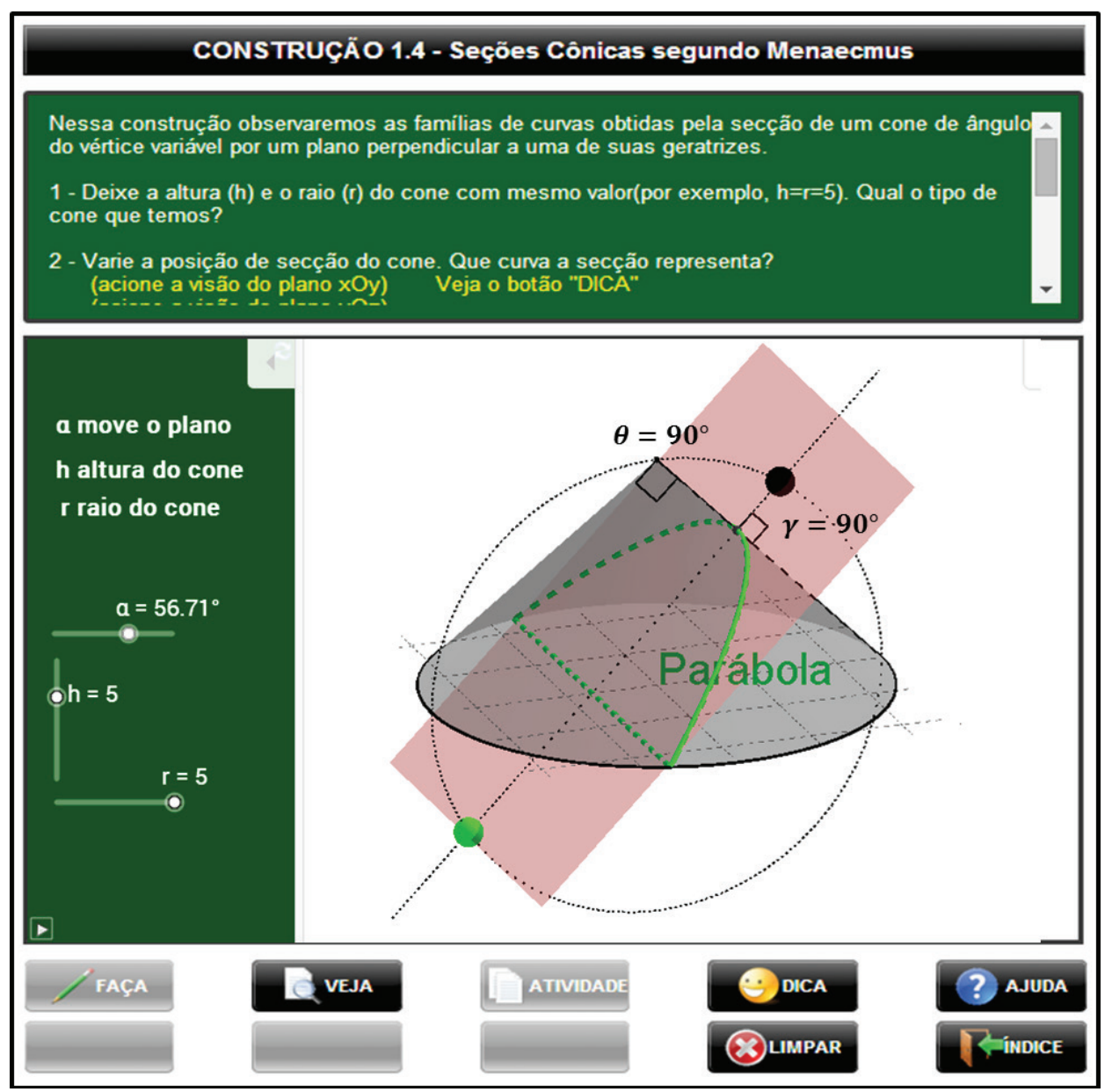

Figura 2: Obtenção das seções cônicas por Menaecmus.

mento que é apresentado e analisado mais a frente no ambiente.

Apolônio, a sua época, mostrou sistematicamente que não era necessário tomar secções perpendiculares à geratriz do cone e que de um único cone poderiam ser obtidas todas as três espécies de seções cônicas, simplesmente variando a inclinação do plano de secção, o que possibilitou relacionar as três curvas.

Dessa forma, conforme o ângulo de secção (ângulo entre o plano e o segmento da geratriz que liga o ponto de secção ao vértice do cone) fosse maior, igual ou menor ao ângulo do vértice do cone, a curva obtida da intersecção do plano com a superfície lateral do cone seria respectivamente, uma elipse, uma parábola ou uma hipérbole.

Essas informações são analisadas mediante a exploração de uma construção, cuja imagem do Quadro de Trabalho (QT) pode ser conferida na Figura 3. Nessa construção, em que um cone duplo ( ou cone de "duas folhas", uma descoberta de Apolônio) é seccionado por um plano, pode-se manipular o ângulo de secção do plano $(\alpha)$, a posição em que o plano secciona o cone $(p)$, a altura $(h)$ do cone e o raio $(r)$ de sua base (e consequentemente, o tipo de cone).

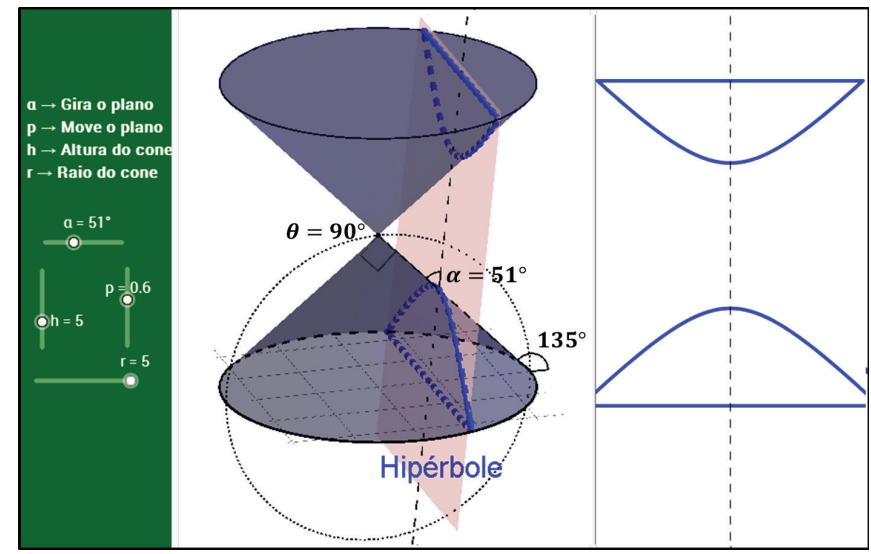

Figura 3: Seções cônicas segundo Apolônio.

Conforme esses valores são alterados, pode-se verificar a curva resultante da interseção da superfície lateral do cone com o plano de secção. As diversas variações possíveis permitem obter ainda, a elipse, a parábola e a circunferência (caso particular de elipse), como se pode ver na sequência de imagens da Figura 4. 


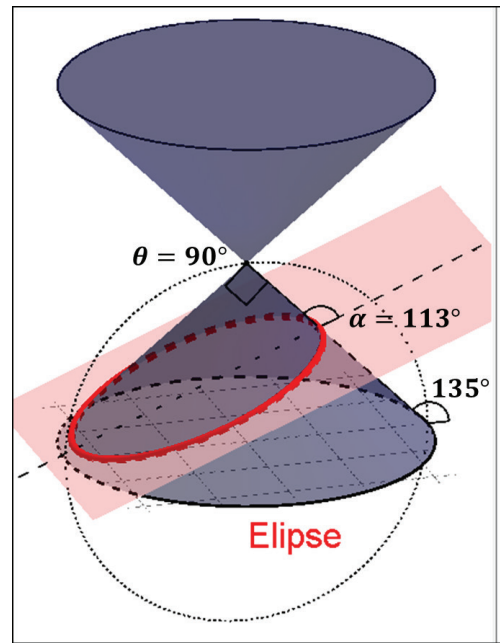

(a) Elipse

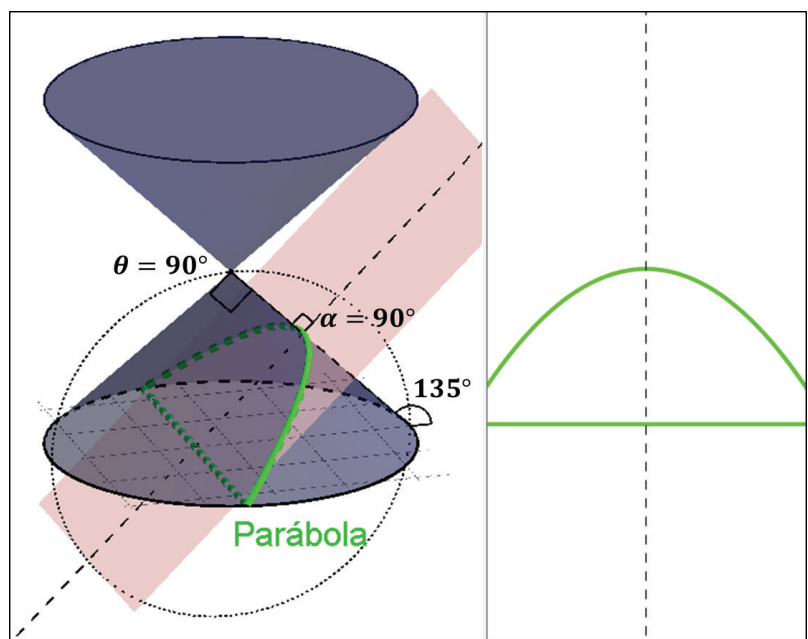

(b) Parábola

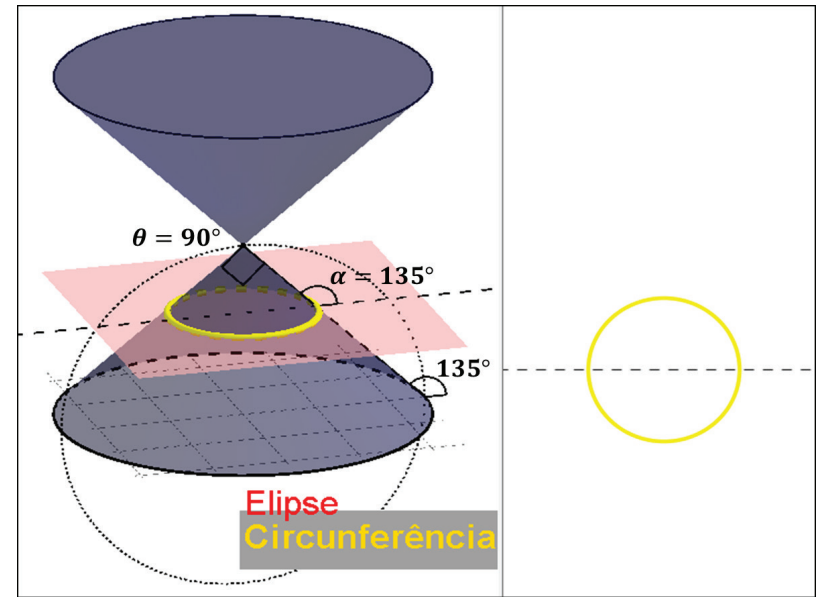

(c) Circunferência

Figura 4: Secções cônicas segundo Apolônio

Essa interação com o objeto e as diversas possibilidades de manuseio permitem ao usuário analisar as informações sobre as definições de cônicas segundo Apolônio, bem como, inferir situações, problemas e conclusões que dificilmente seriam percebidas ao analisar uma figura estática. A visualização do objeto digital em três dimensões, aliada a possibilidade de rotacioná-lo e/ou visualizá-lo em qualquer direção, dão condições inimagináveis de exploração da situação.

\section{Construção: as esferas de Dande- lin.}

Em 1822 o matemático belga Germinal Pierre Dandelin (1794-1847) mostrou que dado um cone K e um plano de secção $\pi$, não contendo o vértice do cone, existe uma ou duas superfícies esféricas $S_{1}$ e $S_{2}$ que se inscrevem no cone ao longo dos círculos $c_{1}$ e $c_{2}$ de tangência com a superfície lateral do mesmo e são tangentes ao plano $\pi$ nos pontos $F_{1}$ e $F_{2}$. Essas superfícies esféricas ficaram conhecidas como esferas de Dandelin.

O matemático Dandelin mostrou ainda que se a seção cônica é uma hipérbole ou elipse (exceto o caso particular da circunferência), então existirão duas superfícies esféricas inscritas no cone e tangentes ao plano; se a seção cônica é uma parábola, será apenas uma superfície esférica.

Para auxiliar na compreensão e analise dessas informações, o ADESC apresenta uma construção em que é possível observar as famosas esferas de Dandelin, conforme descrito acima, para os diversos tipos de seções cônicas. O Quadro de Trabalho (QT) dessa construção pode ser visto na Figura 5.

Na Figura 5(a), mais uma vez, tem-se diversas possibilidades de manipulação do objeto digital e a existência das esferas de Dandelin, nesse caso específico da Hipérbole. Em 5(b) foi desmarcado a opção "Esferas" e 


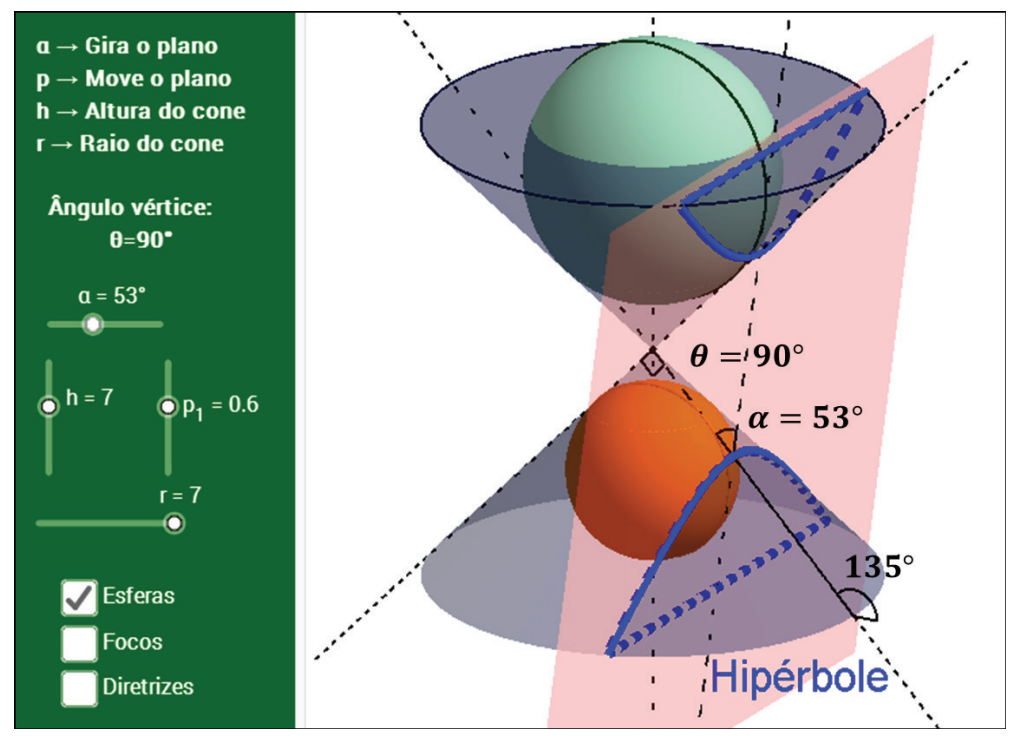

(a) Esferas

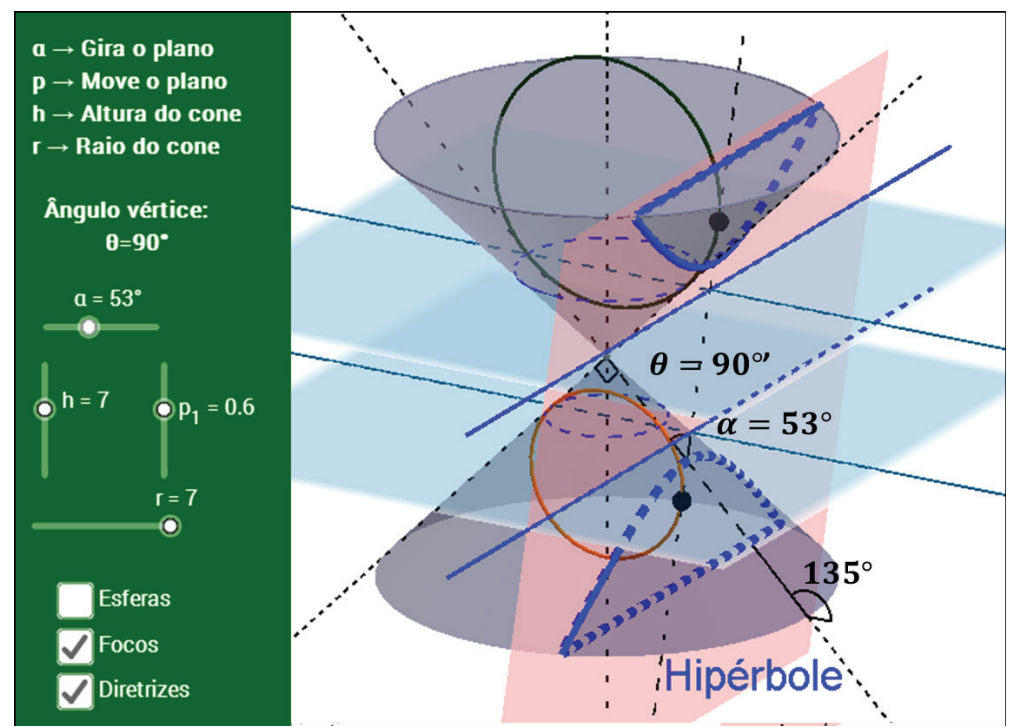

(b) Foco e diretrizes

Figura 5: esferas de Dandelin para a hipérbole.

marcado as opções "Focos" e "Diretrizes".

Manipulando esse objeto, o usuário tem condições de analisar a existência de uma ou duas esfera de Dandelin em cada caso de cônica: elipse, parábola ou hipérbole. Pode ainda comprovar quantos focos e diretrizes possuem cada uma das curvas.

Essa construção certamente facilita a compreensão da definição da reta diretriz de uma cônica, a saber: é a reta resultante da interseção do plano de secção $\pi$ com o plano que contém a circunferência $c$ de interseção da esfera de Dandelin $S$ com a superfície lateral do cone $K$.

Dessa forma e a partir da manipulação da inclinação do plano de secção e obtenção das diversas cônicas, o usuário pode ter uma visão concreta de como e porque variam o número de focos e diretrizes das curvas. Assim, pode-se concluir que a parábola tem apenas um foco e uma reta diretriz, enquanto a hipérbole e a elipse (exceto no caso particular da circunferência, também verificado na construção) possuem dois focos e duas retas diretrizes. Esse tipo de visualização favorece uma investigação detalhada e segura da relação entre os elementos do objeto, dando uma base visual concreta para a elaboração de hipóteses e uma segurança para o surgimento de argumentos geométricos que poderão posteriormente ser analisados à luz da prova matemática. 


\section{Construção: definição usual das cô- nicas.}

As esferas de Dandelin são um ótimo instrumento para provar propriedades analíticas sobre os elementos das cônicas. Assim, por exemplo, a definição usual de elipse como o lugar geométrico dos pontos do plano cuja soma das distâncias a dois pontos fixos dados deste mesmo plano é constante, pode ser facilmente verificada mediante argumentos geométricos básicos e a utilização das esferas de Dandelin. A manipulação de um objeto digital torna essa tarefa ainda mais compreensível.

Assim, no ADESC, antes mesmo de ser apresenta a definição usual de elipse acima mencionada, o usuário se depara com uma construção cuja manipulação leva-o a inferir essa propriedade da curva. Veja a Figura 6.

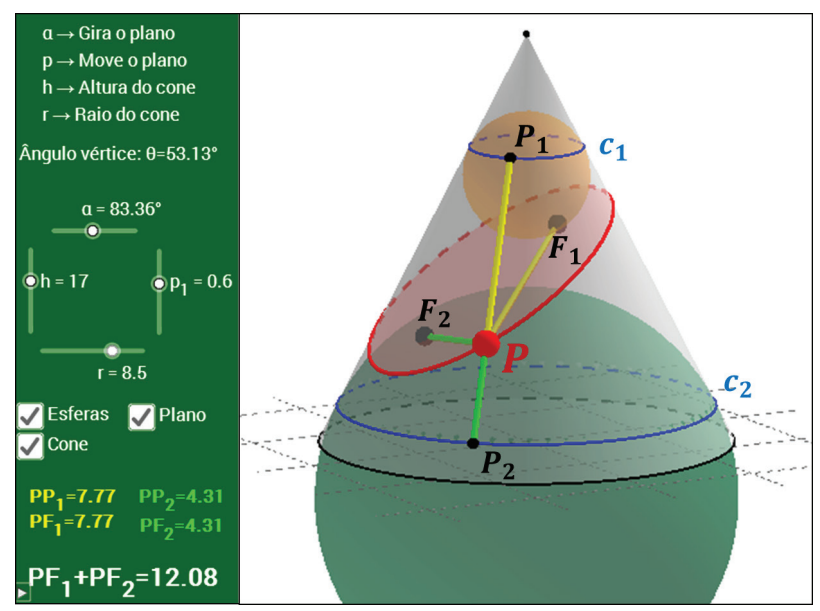

(a) Plano, cone e esfera

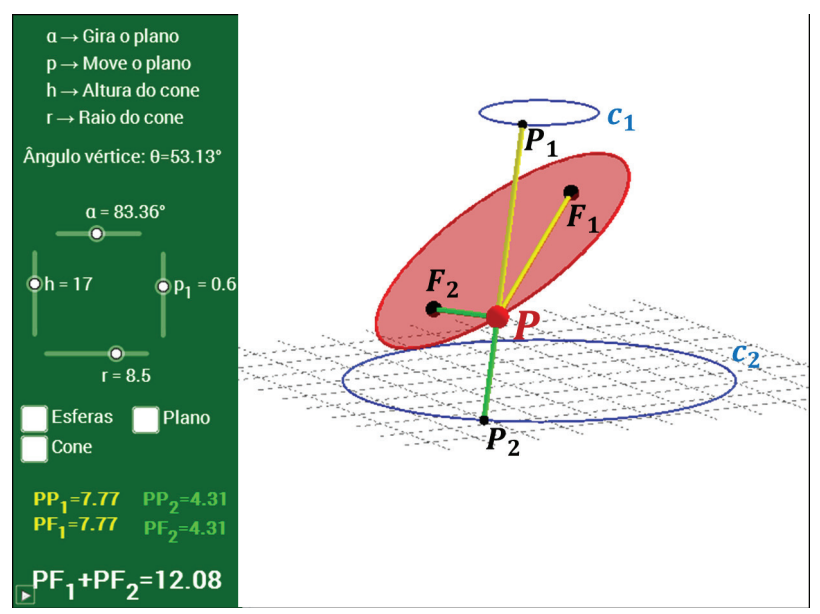

(b) Sem alguns elementos

Figura 6: Definição usual de elipse.

Nessa construção, como acontece nas anteriores, os valores dos elementos do cone e plano são de livre manipulação, bem como a posição do objeto e a visão que se deseja obter do mesmo, já que é possível girá-lo em qualquer direção. É ainda possível, visualizá-lo segunda as vistas dos eixos: $x \mathrm{O} y, x \mathrm{Oz}, y \mathrm{Oz}$. Os botões para essas opções de visualização não estão presentes na Figura 6, pois aparecem na moldura da construção, o que foi suprimido na figura.

Os pontos e segmentos de reta da Figura 6(a) foram obtidos seguindo os passos:

1. Escolheu-se um ponto $P$ qualquer da elipse $E$;

2. Traçou-se pelo vértice $V$ do cone e o ponto $P$ da elipse uma geratriz $g$ do cone;

3. Marcou-se os pontos $P_{1}$ e $P_{2}$, respectivamente interseção da geratriz $g$ com as circunferências de tangências $c_{1}$ e $c_{2}$ das esferas $S_{1}$ e $S_{2}$ com a superfície lateral do cone.

Da análise dessa construção, percebe-se que os seguimentos $\overline{P P_{1}}$ e $\overline{P F_{1}}$ (segmentos na cor amarelo) são tangentes à esfera $S_{1}$ (o primeiro está contido na superfície do cone e o segundo no plano de secção) e $\overline{P P_{2}}$ e $\overline{P F_{2}}$ (segmentos na cor verde) são tangentes à esfera $S_{2}$ (o primeiro está contido na superfície do cone e o segundo, no plano de secção). Assim, como $P$ é exterior às esferas, então, conclui-se que:

$$
\begin{aligned}
& \overline{P F_{1}}=\overline{P P_{1}} \\
& \overline{P F_{2}}=\overline{P P_{2}}
\end{aligned}
$$

(a prova desse fato é feita previamente no próprio ambiente ADESC por meio da semelhança de triângulos.)

Somando (1) e (2), temos:

$$
\overline{P F_{1}}+\overline{P F_{2}}=\overline{P P_{1}}+\overline{P P_{2}}
$$

Como o segundo membro de (3) é o comprimento da geratriz do tronco de cone reto com base nas circunferências $c_{1}$ e $c_{2}$ e este valor é constante (no ambiente é mostrado anteriormente que as geratrizes de um tronco de cone reto são todas iguais), independente da posição do ponto $P$, então:

$$
\overline{P F_{1}}+\overline{P F_{2}}=2 a
$$

onde $2 a$ é uma constante.

Prova-se mais adiante no ambiente que essa constante é maior que a distância entre os focos. Mas esse fato já pode ser percebido, bastando para isso, um olhar atento no triângulo $\triangle P F_{1} F_{2}$ da Figura $6(\mathrm{~b})$ e o conhecimento da propriedade básica da desigualdade sobre os lados de um triângulo qualquer. Não seria fascinante o aluno perceber esse fato antes mesmo do seu enunciado? Essa, entre outras diversas contribuições para o ensino, sobretudo de matemática, é o propósito maior da exploração dos objetos digitais em ambientes dinâmicos. 
Voltando à exploração da construção, o usuário, no desejo de torna-se convicto da igualdade (4), pode movimentar o ponto $P$ sobre a elipse e perceber que a soma $\overline{P F_{1}}+\overline{P F_{2}}$ é sempre constante, independente da posição de $P$, mesmo que os comprimentos de $\overline{P F_{1}}$ e $\overline{P F_{2}}$ se alterem continuamente conforme $P$ é movimentado. Isso pode ser verificado observando os valores desses segmentos no lado esquerdo inferior da construção.

Alterando a elipse (o que pode ser feito variando o ângulo de inclinação do plano de secção) pode-se perceber que a soma $\overline{P F_{1}}+\overline{P F_{2}}$ assume valores diferentes para os diferentes formatos de elipse, no entanto, é sempre igual para qualquer ponto da mesma curva.

Na Figura 6(b) foram desmarcadas as opções "Cone" e "Esfera". Nessa situação, vemos que a construção fica mais limpa e favorável à análise das relações entre os seus elementos.

A mesma análise acima feita para o caso da elipse, também é feita antes da definição formal de Parábola e Hipérbole. Veja na Figura 7, as construções referentes à essas cônicas com seus respectivos elementos.

Da análise e exploração desses objetos é possível concluir, mediante argumentos geométricos simples, sobre as definições usuais de parábola e hipérbole, como se segue:

Parábola: é o lugar geométrico dos pontos do plano que são equidistantes a uma reta e a um ponto (não pertencente à reta), dados.

Hipérbole: é o lugar geométrico dos pontos do plano cuja a diferença das distâncias a dois pontos fixos dados é constante.

\section{Construção: método do jardineiro.}

Definida as cônicas como lugar geométrico dos pontos do plano que possuem determinadas propriedades, é possível obtê-las mecanicamente no plano utilizando-se de alguns instrumentos.

Na Figura 8 temos o quadro de trabalho de uma construção do ambiente ADESC em que se mostra como desenhar uma elipse por meio de lápis, corda e alfinetes, processo conhecido popularmente como "Método do Jardineiro". Veja o passo a passo:

1. Fixe os dois focos da elipse no plano (alfinetes);

2. Fixe as extremidades de uma corda nos focos;

3. Com a ponta de um lápis estique a corda e movimente-o em torno dos focos com a corda sempre esticada.

Enquanto o lápis é movimentado a elipse vai sendo desenhada e os valores dos seguimentos são alterados

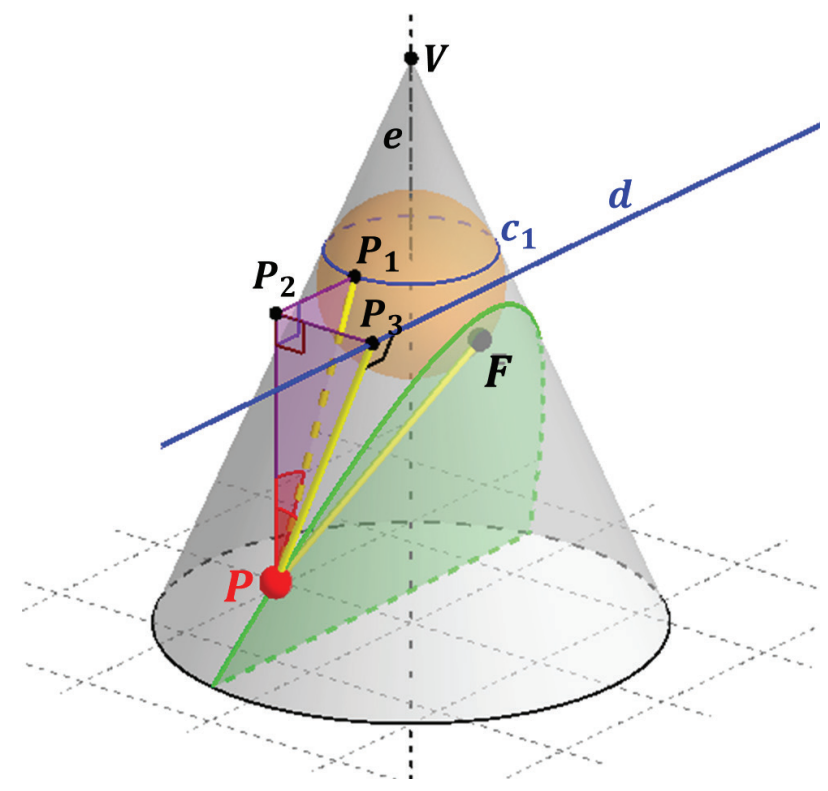

(a) Parábola

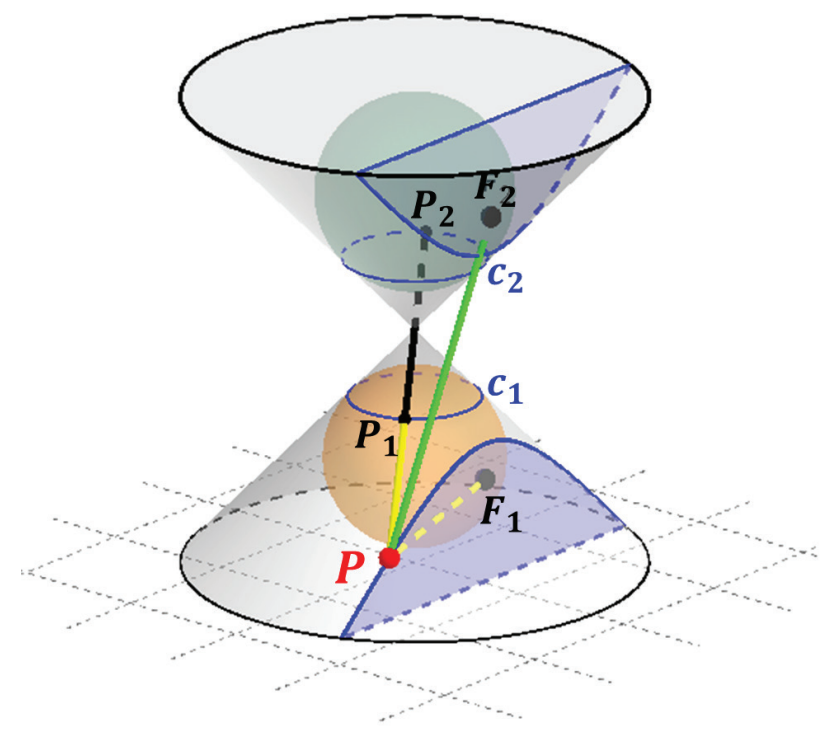

(b) Hipérbole

Figura 7: Definição usual de parábola e hipérbole.

continuamente. O movimento do lápis pode ser acionado automaticamente por meio do botão "Player", presente na moldura da construção ou simplesmente clicando sobre o lápis e movimentando-o livremente até onde a corda permitir.

O dinamismo da construção permite alterar o tamanho da corda e da distância focal, possibilitando ao usuário analisar os formatos da elipse conforme se altera esses elementos constituintes.

Muitas outras análises podem ser feitas com esse objeto e suas possíveis manipulações.

O mesmo processo de construção e o passo a passo 


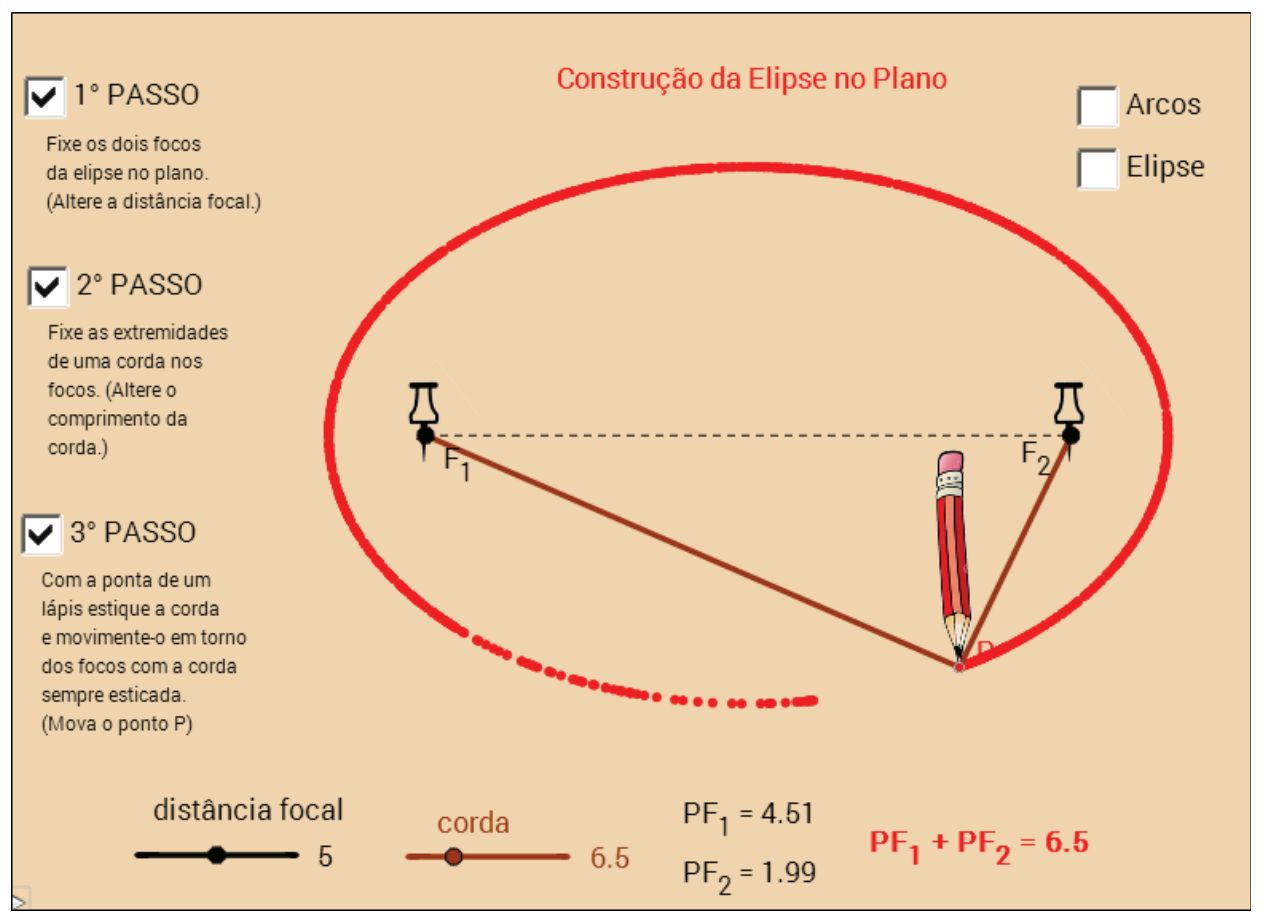

Figura 8: Construção da elipse pelo método do jardineiro.

também é mostrado para o caso da parábola e da hipérbole, como se pode verificar na Figura 9. Aqui, outras diversas análises e exploração também podem ser feitas para essas curvas e seus elementos constituintes. Portanto, o usuário pode alterar livremente os elementos da construção e observar a relação que esses elementos mantém com o formato da curva, seja ela a parábola ou a hipérbole.

\section{Conclusão}

O ADESC possibilita um estudo participativo das cônicas, em que o conhecimento é fruto de um processo investigativo e exploratório. Assim, de maneira ativa, o usuário é levado numa viagem pelo mundo das seções cônicas, conhecendo desde as suas origens históricas, passando pelas primeiras formas de obtenção das curvas, as propriedades analíticas e, mesmo não tendo sido explorado neste artigo, vale ressaltar que o ambiente ainda dispõe de construções que permitem os usuários conhecerem as propriedades refletoras das superfícies cônicas e suas diversas aplicações nas ciências modernas.

Portanto, acreditamos fielmente na contribuição positiva que esse ambiente dinâmico pode dar aos professores que passarem a utilizá-lo como ferramenta de apoio nas suas aulas de cônicas.

Para um bom uso do ambiente, recomendamos que o professor utilize o projetor de mídia e o laboratório de informática da escola, onde os alunos de posse do computador com o ADESC, possam manusear e interagir com o ambiente, sempre sobre a observação e orientação do professor, que deverá ser o guia da turma, fazendo a sua exploração do ambiente e projetando a imagem de forma que a turma possa segui-lo de perto, em cada passagem do conteúdo.

O ambiente é instrutivo e foi concebido para ser autoexplicativo. No entanto, o professor deve conduzir seus alunos na exploração do mesmo. Ele deve conduzir o processo de aprendizagem paulatinamente, de forma que todos os alunos caminhem juntos na descoberta do mundo das cônicas.

Para ser um bom guia é imprescindível que o professor adquira conhecimento prévio dos conteúdos presentes no ADESC. A recomendação, nesse caso, é que se faça um estudo atento da proposta de conteúdos sobre as cônicas apresentada em LIMA (2014), buscando maiores informações nos materiais de referência ao final desse artigo sempre que julgar necessário. É, ainda, de extrema importância que o professor adquira familiaridade com o ADESC e seus elementos, o que pode ser conseguido lendo o manual do ambiente presente na página "Home" do mesmo, ao passo que faz a sua exploração e manipulações.

Sabemos que no que tange ao ensino, as mudanças não são fáceis e nem tão pouco se dão de forma imediata, principalmente quando tais mudanças visam romper com o tradicional e que de certa forma está enraizado como o correto a se fazer. Porém, não devemos esquecer que a sociedade é um sistema em constante transformação, o que gera grandes mudanças no individuo em seu 


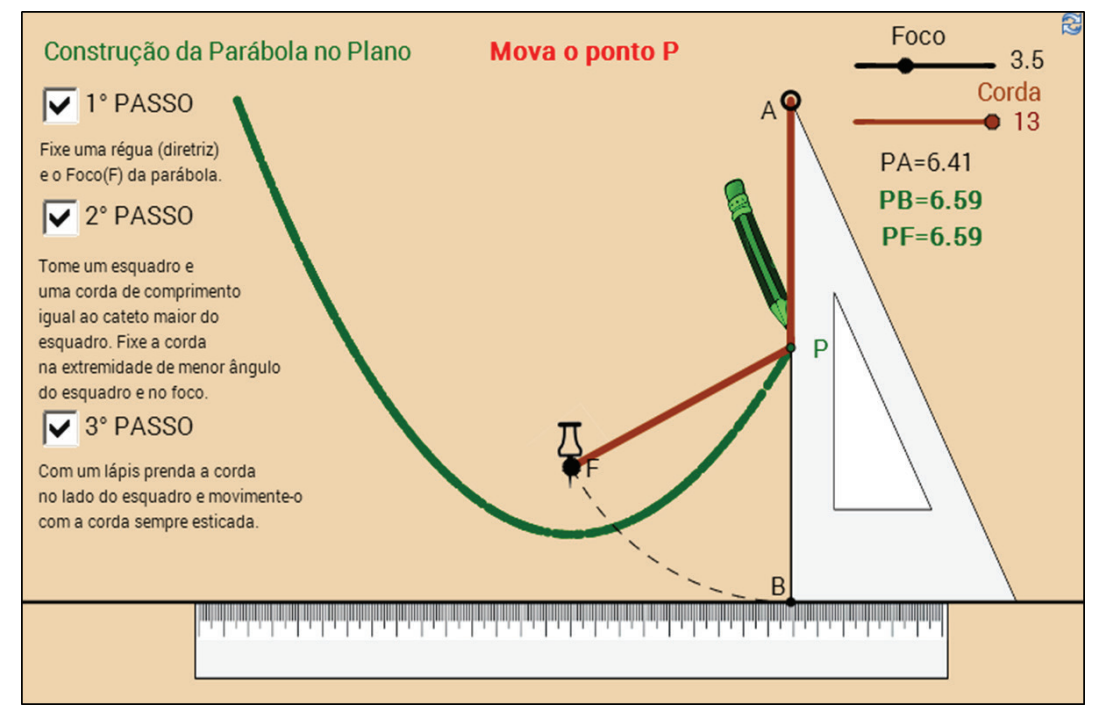

(a) Parábola

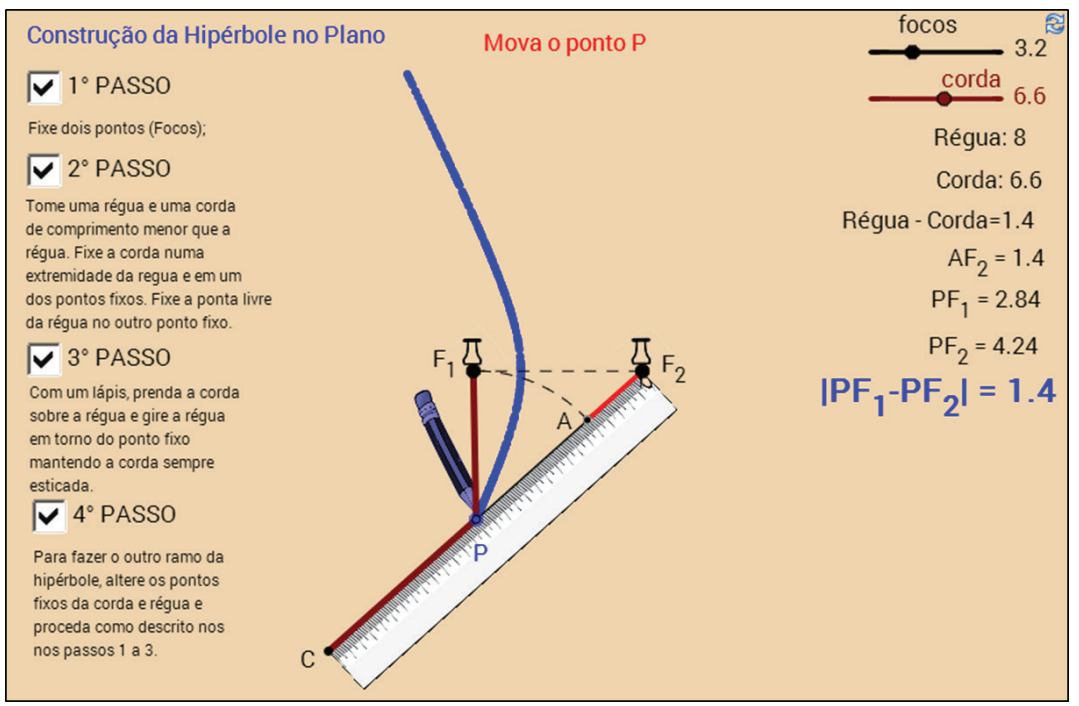

(b) Hipérbole

Figura 9: Método do jardineiro.

modo de pensar, agir e interagir no meio em que vive. Logo, fica evidente que o ensino da Matemática, assim como o ensino de outras áreas do conhecimento, não deve permanecer inerte a esta necessidade de inovação tão evidente na falta de interesse dos alunos nos estudos.

Tem-se total consciência que as contribuições feitas para o ensino das cônicas por meio do ADESC não são suficientes e terminativas e que muito ainda precisa ser revisto, reformulado ou reestruturado no ensino das seções cônicas. Contudo, espera-se que o leitor tenha se sentido instigado a analisar e refletir sobre sua prática didática e sobre a importância de incrementá-la com o uso dos recursos das TIC's, procurando fazer o mesmo tipo de exploração que aqui foi proposto para o ensino das cônicas, nos diversos outros temas do ensino básico.

\section{Referências}

(2014). Adesc. URL http://www . adesc.blog.br.

Boyer, C. B. (1996). História da Matemática, $2^{\circ}$ edn. Edgard Blücherl.

D’ambrósio, U. (2003). Novos paradigmas de atuação e formação de docente, $2^{\circ}$ edn. JM Editora.

LIMA, J. P. (2014). Uma proposta para o ensino das seções cônicas no ensino básico mediante o uso de um ambiente dinâmico. Dissertação, Universidade Federal Rural do Semi-árido, UFERSA. 